\title{
Effects of age on organization and recall of two sets of stimuli'
}

HARVEY A. TAUB AND SHIRLEY GREIFF

SYRACUSE VA HOSPITAL AND STATE UNIVERSITY OF NEW YORK, UPSTATE MEDICAL CENTER

Short-term recall of sequences of 8 letters was measured for 12 young and 12 aged $S$ s in a control condition with a single stimulus set and three experimental conditions which differed in arrangement of two sets of color-coded stimuli. The results indicated that there were no differences in performance for the stimuli to be recalled first, while both age and conditions were significant effects for the stimulus set to be recalled second.

Previous studies of age-related differences in the recall of two sets of material utilized stimuli which were alternated sequentially or presented simultaneously to two sensory channels (Broadbent \& Gregory, 1965; Inglis, 1965). The general results of these studies were that no differences were found for simple single channel spans, but that performance varied inversely as a function of age on the dual channel tasks. Inglis (1965) has further established that with the dichotic listening technique no differences are apparent in the half span which is recalled first, but that significant age-related decrements occur in the recall of the second half span. These second half effects were attributed to a combination of increased rate of memory decay and greater susceptibility to interference as age increases.

On the other hand, the finding that recall of the second half set varied inversely with age even when the number of stimuli for the two sets combined was well below the simple span (Inglis, 1965) suggests that differential decay is less relevant as an explanation than susceptibility to interference (Taub, 1966) and decline in organizing capacity (Friedman, 1966). Further, Friedman's finding (1966) of age-related decrements when single channel spans were exceeded suggests that both single and dual channel tasks lie on a continuum of required stimulus organization and that both should produce similar decrements once maximum capacity for the task has been exceeded. If this is the case, then presenting more stimuli than can be correctly recalled in a single channel task (e.g., eight letters) should produce effects similar to those of Inglis (1965). This hypothesis was investigated using both a single stimulus set and two half sets of color-coded binocularly-viewed stimuli which were presented sequentially.

Method

The Ss consisted of 12 young and 12 aged female volunteers with mean ages of 20.1 and 69.7 years, respectively. The two age groups were equated so that they did not differ significantly on the Vocabulary,
Digit Span, and Digit Symbol subtests of the Wechsler Adult Intelligence Scale.

A Lafayette memory drum was used to present the letter sequences at the rate of 1 sec. per letter. Each series or sequence consisted of eight letters of the alphabet. Six series were devised for each of four conditions and typed onto a continuous belt of paper. To provide for two different populations of stimuli, the letters $A-K$ were always typed in black while the letters $\mathrm{P}-\mathrm{Z}$ were always typed in red. The four experimental conditions differed in terms of the arrangement of red and black letters in the sequences. In Condition 1 (Control) each series contained all red or all black letters. Three of the series were red and three were black. In Condition 2 (Halves) each series contained four randomly chosen red (P-Z) and black $(A-K)$ letters arranged in the order RRRRBBBB in three of the series and BBBBRRRR in three of the series. In Condition 3 (Blocks of Two) the arrangements of the red and black letters were RRBBRRBB in three of the series and BBRRBBRR in the other three series. In Condition 4 (Alternation) the red and black letters were arranged in alternating patterns of RBRBRBRB in three of the series and BRBRBRBR in the other three series. Condition 1 was the normal short-term recall situation where Ss observed only one type of stimuli in each sequence and were required to report the sequence in the order in which it was presented. In Conditions 2-4, Ss were assigned a color to report first and were further instructed that regardless of arrangement of colored letters in a series, the letters of the assigned color must always be reported in order before the letters of the second colored set.

All Ss in both age groups were individually tested with all six series in all four of the conditions. Further, each $S$ completed all six trial series in a particular condition before viewing series from the other conditions. To control for possible practice effects, three Ss from each age group were assigned to each order in a 4 by 4 latin square design. Before the start of each new condition, Ss were (a) shown a card with examples of sequences for that condition, (b) told what a perfect answer would be, and (c) given examples of acceptable answers if all letters could not be recalled. Finally, before each series, Ss were shown a sample card which illustrated the arrangements of the letters on that trial.

All reports of the letters were made verbally and recorded by the experimenter. The reporting interval 
was subject-paced so that the next trial did not begin until $S$ indicated that her report was completed and was ready for the next series.

\section{Results and Discussion}

The data were scored for the number of letters in the first and second half sets which were correctly reported regardless of the order in the report. For example, if the red letters were to be reported first and $\mathrm{Ss}$ reported $\mathrm{R} 1, \mathrm{R} 2, \mathrm{~B} 1, \mathrm{R} 3, \mathrm{~B} 3, \mathrm{R} 4$, then $\mathrm{S}$ would be given a score of four correct for the first half span and two correct for the second half span. The data were also scored for number correct in order for each half span although with the verbal mode of reporting it was sometimes difficult to determine when $S$ completed her report of the first half set and began reporting the second. Since the two measures led to identical trends and statistical effects, only the results from the less arbitrary measure of no order will be reported.

The number correct without regard to order was summed over six series resulting in a single score for each condition. Separate latin square analyses were performed on the data for each half set. The analysis for the half set which was to be reported first indicated that the only significant effect was an improvement in performance of both age groups attributable to

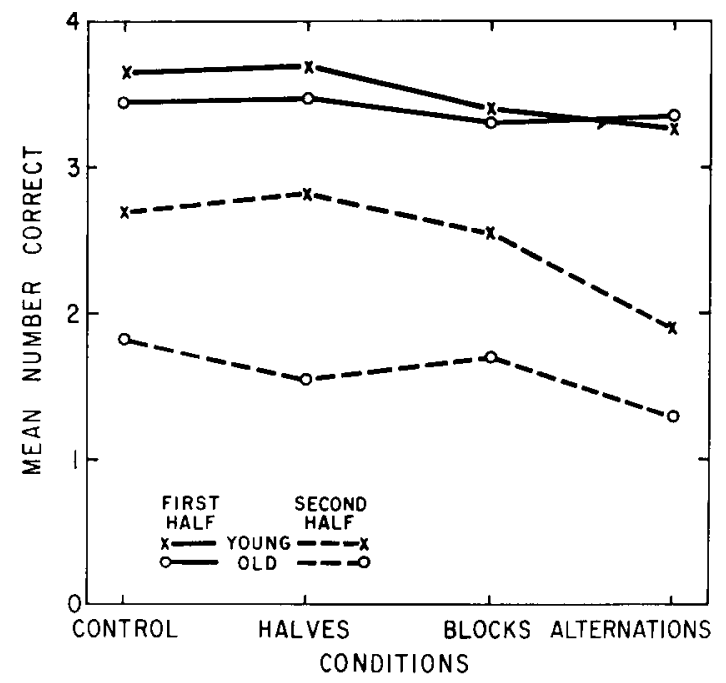

Fig. 1. Mean number correct without regard to order for first and second half reports as a function of Age and Conditions. practice $(F=4.01, \mathrm{df}=3 / 48, \mathrm{p}<.05)$. There were no differences in performance due to Age or to Conditions. Analysis of the second half set indicated that aside from a similar practice effect $(\mathrm{F}=4.36, \mathrm{df}=3 / 48$, $p<.01)$, Age $(F=19.50, d f=1 / 16, p<.01)$, Conditions $(\mathrm{F}=10.76, \mathrm{~d} f=3 / 48, \mathrm{p}<.01)$ and latin square sequence $(F=4.91, \mathrm{df}=3 / 16, \mathrm{p}<.01)$ also produced differences in performance. Figure 1, a presentation of the mean scores for Age and Conditions within each half set, illustrates the lack of effect for the first half set and further shows that for the second half set the older Ss did poorer than the younger Ss under all conditions and that the effect of conditions was due to a reduction in performance as the arrangement of the stimuli changed from Halves to Alternation.

In general, the effects due to age confirm the findings of Inglis (1965) in showing a significant agerelated decrement for the second half sets, but no differences in the stimuli to be reported first. Further, the present results extend the previous literature by suggesting that age-related decrements will occur on second half reports of single channel stimuli if the span or capacity has been exceeded. Finally, using the "time in storage" example devised by Inglis (1965), the finding of a significant second half difference with the control condition would suggest that agerelated decrements occur even with equal time in storage. Thus, the data do not support the notion of differential decay as a function of age, but are consistent with the suggestions of a decline in organizing capacity (Friedman, 1966) and a greater susceptibility to interference during the storage and retrieval phases once the capacity is exceeded (Taub, 1966).

\section{References}

Broadbent, D. E., \& Gregory, M. Some confirmatory results on age differences in memory for simultaneous stimulation. Brit. $J$. Psychol., 1965, 56, 77-80.

Friedman, H. Memory organization in the aged. J. genet. Psychol., $1966,109,3-8$.

Inglis, $\mathbf{J}$. Immediate memory, age and brain function. In $A . T$. Welford \& J. E. Birren (Eds.), Behavior, aging and the nervous system. Springfield, Ill.: Charles C. Thomas, 1965.

Taub, H. A. Visual short-term memory as a function of age, rate of presentation and schedule of presentation. J. Geront., 1966, $21,388-391$.

\section{Note}

1. This research was supported in part by U. S. Public Health Service General Research Support Grant FR-5402 to the State University of New York Upstate Medical Center. 